\title{
STUDY ON QSSR WITH THE ATOMIC IONICITY INDICES
}

\author{
YAXIN WU ${ }^{1}$, CHANGMING NIE*,, RONGYAN WU' ${ }^{2}$ SAIHONG JIANG ${ }^{1}$, SONGNIAN WEN ${ }^{1}$
}

${ }^{1}$ School of Chemistry and Chemical Engineering, University of South China, Hengyang, Hunan Province 421001
${ }^{2}$ School of Nuclear Science and Technology, University of South China, Hengyang, Hunan Province 421001 (Received: September 12, 2007 -Accepted: April 29, 2008)

\begin{abstract}
In this paper, we find that stretching vibration frequencies of the $\mathrm{X}=\mathrm{O}$ for series of $\mathrm{R}_{1} \mathrm{R}_{2} \mathrm{C}=\mathrm{O},(\mathrm{RO})_{2} \mathrm{CO}, \mathrm{RCO}_{2} \mathrm{H}, \alpha$-halogenated aldehydes, cross-RONO and $\mathrm{R}_{2} \mathrm{NNO}$ can be described by the ionicity indices of $\mathrm{X}$ and $\mathrm{O}$ atoms as follows: $v=\mathrm{a} I N I_{(\mathrm{O})}+\mathrm{b} I N I_{(\mathrm{X})}+\mathrm{c}$, where $\mathrm{a}, \mathrm{b}, \mathrm{c}$ are regression constants, and $I N I_{(\mathrm{X})}, I N I_{(\mathrm{O})}$ represent the ionicity indices of $\mathrm{X}$ and $\mathrm{O}$ atoms. The efficiency of the model is verified by high correlation coefficients in the range of $0.960-1.000$. Similarly, the ultraviolet absorption energy of ketones can also be characterized by the ionicity indices of $\mathrm{C}$ and $\mathrm{O}$ as $\Delta E=\mathrm{a} I N I_{(\mathrm{O})}+\mathrm{b} I N I_{(\mathrm{C})}+\mathrm{c}$. The predicted results are in good agreement with the experimental ones. Furthermore, the good stability and powerful predictive ability of those models are proved by LOO method.
\end{abstract}

Keywords: stretching vibration frequency; ultraviolet absorption spectrum; $\mathrm{X}=\mathrm{O}$ bond; ionicity index

\section{INTRODUCTION}

Since the Wiener index $W$ introduced in $1947^{1}$, the topological indices have performed an important role in quantitative structure-activity/property relationships (QSAR/QSPR) study. Many researchers gave much attention to investigations on QSAR, QSPR, QSRR, etc ${ }^{2-8}$. The topological chemistry and structural information parameters have been widely applied to biopharmaceutics, environmental pollution control and many other fields ${ }^{9-17}$.

Bajaj Sanjay ${ }^{15}$ proposed a novel highly discriminating adjacency-cumdistance based topological descriptor, termed it as augmented eccentric connectivity index and investigated the discriminating power of the index in predicting the anti-HIV activity of 2-pyridinone derivatives. The discriminating power of the augmented eccentric connectivity index was found to be superior to that of the distance based Wiener's index and adjacency based molecular connectivity index. Roy Kunal ${ }^{16}$ proved the quantitative structure-toxicity relationship (QSTR) study to be a valuable approach in ecotoxicity estimations of acute and chronic toxicity to various organisms, and in fate estimations of physical/chemical properties, degradation, and bioconcentration. In the study, he modeled the inhibition of 41 substituted phenols on germination rate of Cucumis sativus with extended topochemical atom $(E T A)$ indices, and indicated that ETA descriptors are sufficiently rich in chemical information to encode the structural features contributing significantly to the comparative inhibition activity of substituted phenols on germination rate of Cuicumis sativus. Dureja $\mathrm{H}^{17}$ studied the relationship between the topochemical indices and permeability of diverse series of compounds through blood-brain barrier and compared the three-topochemical indices, Wiener's topochemical index, molecular connectivity topochemical index and eccentric connectivity topochemical index in his investigation. Accuracy of prediction was found to vary from a minimum of $83 \%$ to a maximum of similar to $95 \%$ using these models.

Recently, the study on quantitative structure-spectrum relationship (QSSR) has attracted widespread attention. ${ }^{18-21}$ Zhongchen $\mathrm{Cao}^{18}$ studied polarizability effect of alkyl group on the stretching vibration frequency for $\mathrm{X}=\mathrm{O}$ bond. Khadikar P. ${ }^{19}$ estimated the characteristic vibration of carbonyl group by using the Szeged index. You Jinglin ${ }^{20}$ composed the novel topological index SIT to depict the Raman spectra of silicate glasses and their liquids. Zhou L. P. ${ }^{21}$ investigated the prediction of carbon-13 NMR chemical shifts of alkanes with rooted path vector, and got a good result. On the basis of previous work ${ }^{22-30}$, we put forward new QSSR models on the ground of the ionicity indices ${ }^{22}$ of $\mathrm{X}$ and $\mathrm{O}$ atoms, and use these models to study the law of change for infrared stretching vibration frequencies of $\mathrm{X}=\mathrm{O}$ and the ultraviolet absorption energy of $\mathrm{C}=\mathrm{O}$.

\section{Theories and Methods}

1 Model Development

In this paper, we consider using the ionicity indices of atoms in $\mathrm{X}=\mathrm{O}$ to depict the change rule of the spectral property of compounds with $\mathrm{X}=\mathrm{O}$ and build a multiple linear regression (MLR) model as follows:

$$
P=\mathrm{a} N N_{(0)}+\mathrm{b} I N L_{(\mathrm{X})}+\mathrm{c}
$$

where a, b, c are regression constants. $P$ represents the spectral property of compounds with $\mathrm{X}=\mathrm{O}$. The correlation coefficient $(R)$, the Fischer ratio value
$(F)$, and the determinant constant $(S)$ can be used to assess the quality of the models. $I N I_{(\mathrm{O})}$ and $I N I_{(\mathrm{X})}$ are the ionicity indices of the atom $\mathrm{O}$ and $\mathrm{X}$.

2 Ionicity indices

Authors ever pointed the ionicity indices $\left(X_{I N I}\right)^{22}$ of atoms in molecule as

$$
X_{I N I}=\left|\left(X_{E}-X_{A}\right) / X_{A}\right| \times 100
$$

In the Equation (2), $X_{A}$ is Pauling electronegativity scale, and $X_{E}$ is the atomic equilibrium electronegativity ${ }^{23}$ in molecule. $X_{E}$ is figured as

$$
X_{E}=\left(X_{A}+\sum X_{G}\right) /\left(1+\sum l\right)
$$

In the Equation (3), $\sum 1$ is the sum of atoms or branching groups directly attached to the atom, and $\sum X_{G}$ is the sum of electronegativities of atoms or groups directly attached to the atom. $X_{G}$ is given by the following ${ }^{24}$ :

$$
X_{G}=\left\{\frac{1}{n_{13}} \sum_{i=1}^{n_{4}} \frac{1}{n_{2 l}}\left[\sum_{i=1}^{n_{2}} \cdots\left(\frac{1}{n_{k j}} \sum_{i=1}^{n_{4}} X_{k j}\right) \cdots\right]\right\}
$$

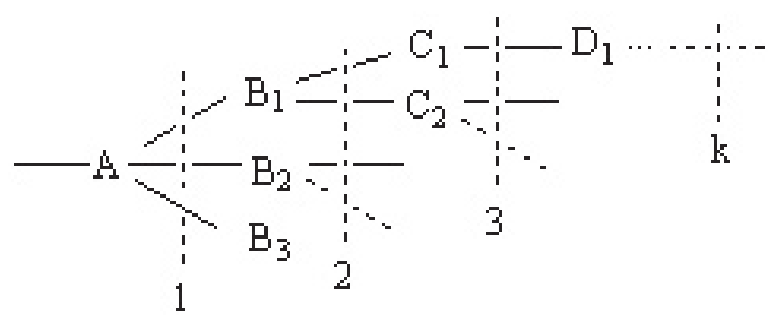

Fig. 1 Schematics of group structure

As shown in Fig. 1, the group can be divided into $k$ layers, and the left atoms of the dotted line labeled $1,2,3, \ldots k$ are known as the ground atoms. The right suffix of atoms $l$ is the numeration of the ground atom. $n_{l l}, n_{2 l} \ldots n_{k l}$ are the sum of the ground atom $l$ and other atoms or groups directly attached to the ground atoms in the grade $1,2,3, \ldots k . \sum_{l_{i=1}}^{n_{4}} X_{11}, \sum_{l=1}^{n_{4}} X_{2 l}, \ldots \sum_{l=1}^{n_{4}} X_{k l}$

are the sum of electronegativities of the ground atom $l$ and other atoms or branching groups directly attached to the ground atoms in the grade $1,2,3, \ldots k$.

\section{RESULTS AND DISCUSSION}

\section{QSSR study for infrared spectrum}

Scientists began to research into the infrared spectrum in the 20th century. Ordinarily, the infrared absorption frequency of the organism is in the range of $4000-625 \mathrm{~cm}^{-1}$, and contains plentiful structural information. The infrared absorption wave lengths of different functional groups in the organic molecules are different from each other. Affected by the chemical condition around the functional groups, the changing of the position, intensity and shape of the 
absorption band occurs. Application of the infrared spectrum has played a very important part in organic chemistry, biological chemistry and medicinal chemistry, etc. For instance, the infrared spectrum is regarded as a crucial deliberated index for more and more medicines by codex in various countries ${ }^{31}$. Above all, it is very useful and necessary to establish a convenient and exact method to predict the infrared spectrum information in virtue of the quantitative structure-spectrum relationship.

1.1 Relationships between ionicity indices and the values of stretching vibration frequencies

There are many factors influencing on the displacement of the absorption bands, for example, the electronic effect, stereoscopic effect, coupling effect, bond strength, tautomery, hydrogen bond. Researchers found out that the change of the stretching vibration frequencies of the $\mathrm{X}=\mathrm{O}$ bond is mostly determined by the electronic and stereoscopic factors ${ }^{31}$. Many experimental results demonstrated that the variation of the eigen frequency of $\mathrm{X}=\mathrm{O}$ happens mainly because of the impacts of the substituents linked directly to the $\mathrm{X}$ atom, especially the affect of the electronic effect of groups. We believe that the affect can be described with ionicity indices of atom X and $\mathrm{O}$. We replaced $P$ in Equation (1) with the stretching vibration frequencies $(v)$ of the $\mathrm{X}=\mathrm{O}$ and obtained Equation (5).

$$
v=\mathrm{a} N N_{(0)}+\mathrm{b} N N_{(\mathrm{x})}+\mathrm{c}
$$

We made linear simulation of the stretching vibration frequencies of the $\mathrm{X}=\mathrm{O}$ for various series according to the Equation (5) using the known infrared spectrum data ${ }^{31}$. And the followings are obtained:

For series $\mathrm{R}_{1} \mathrm{R}_{2} \mathrm{C}=\mathrm{O}$ :

$v=-1093.2+166.287 I N I_{(\mathrm{O})}+66.889 I N I_{(\mathrm{C})}$

$R=0.978, S=2.923, n=8$.

For series (RO) $\mathrm{CO}$ :

$v=3672.0-91.483 I N I_{(\mathrm{O})}-68.108 I N I_{(\mathrm{C})}$

$R=0.994, S=1.215, n=4$.

For series $\mathrm{RCO}_{2} \mathrm{H}$ :

$v=2915.2-43.033 I N I_{(\mathrm{O})}-70.916 I N I_{(\mathrm{C})}$

$R=1.000, S=0.179, n=4$

For series Cross-RONO:

$v=8499.5-760.992 I N I_{(O)}-577.710 I N I_{(\mathbb{N})}$

$R=0.988, S=1.470, n=10$

For series $\mathrm{R}_{2} \mathrm{NNO}$ :

$v=-15047.5+1885.083 I N I_{(\mathrm{O})}-1187.440 I N I_{(\mathrm{N})}$

$R=0.999, S=1.029, n=4$.

For series $\alpha$-halogenated aldehyde:

$v=79922.4-4533.990 I N I_{(\mathrm{O})}-2236.420 I N I_{(\mathrm{N})}$

$R=0.960, S=7.294, n=5$.

We calculated the stretching vibration frequencies of the $\mathrm{X}=\mathrm{O}$ for 35 compounds by the Equation (6)-(11), and listed the results on the Table 1.The results indicated that the stretching vibration frequencies of the $\mathrm{X}=\mathrm{O}$ were well correlated with the ionicity indices of the atom $\mathrm{O}$ and $\mathrm{X}$, the correlation coefficient $R$ was in the range of $0.960-1.000$, and $S$, the standard deviation was among 0.179-7.294. The relative errors between the calculated values and the experimental ones are under $0.6 \%$.
Table 1.- Comparison of the calculated values with the experimental values of $v$ for 35 compounds

\begin{tabular}{|c|c|c|c|c|c|c|}
\hline Compound & $I N I_{(\mathrm{X})}$ & $I N I_{(\mathrm{O})}$ & $\begin{array}{c}v_{\text {exp }}( \\
\text { Solvent })^{31}\end{array}$ & $v_{\text {calc. }}$ & $\begin{array}{l}v_{\text {exp. }}{ }^{-} \\
v_{\text {calc. }}\end{array}$ & $\begin{array}{c}\Delta E / \\
\%\end{array}$ \\
\hline $\begin{array}{c}{ }^{\mathrm{a}} \mathrm{R}_{1} \mathrm{R}_{2} \mathrm{C}=\mathrm{O} \\
\mathrm{MeCCHO} \\
\mathrm{EtCHO} \\
\mathrm{PrCHO} \\
\mathrm{Me}{ }_{2} \mathrm{CO} \\
\mathrm{i}-\mathrm{PrMeCO} \\
\text { t-BuMeCO } \\
(\mathrm{t}-\mathrm{Bu})_{2} \mathrm{CO} \\
\text { Cyclohexanone }\end{array}$ & $\begin{array}{l}2.7216 \\
2.9373 \\
2.9882 \\
3.5804 \\
4.0078 \\
4.2235 \\
4.8667 \\
4.1490\end{array}$ & $\begin{array}{l}15.9041 \\
15.7965 \\
15.7703 \\
15.4797 \\
15.2674 \\
15.1628 \\
14.8430 \\
15.1977\end{array}$ & $\begin{array}{c}1733\left(\mathrm{CCl}_{4}\right) \\
1730\left(\mathrm{CHCl}_{3}\right) \\
1727\left(\mathrm{Pure}_{3}\right. \\
\text { liquid) } \\
1720\left(\mathrm{CCl}_{4}\right) \\
1718\left(\mathrm{CCl}_{4}\right) \\
1710\left(\mathrm{CCl}_{4}\right) \\
1697\left(\mathrm{CCl}_{4}\right) \\
1714\left(\mathrm{Pure}^{2}\right. \\
\text { liquid) }\end{array}$ & $\begin{array}{l}1733 \\
1730 \\
1729 \\
1720 \\
1714 \\
1711 \\
1700 \\
1711\end{array}$ & $\begin{array}{c}0 \\
0 \\
-2 \\
0 \\
4 \\
-1 \\
-3 \\
3\end{array}$ & $\begin{array}{c}0 \\
0 \\
-0.12 \\
0 \\
0.23 \\
-0.06 \\
-0.18 \\
0.18\end{array}$ \\
\hline $\begin{array}{c}\mathrm{b}(\mathrm{RO})_{2} \mathrm{CO} \\
(\mathrm{MeO})_{2} \mathrm{CO} \\
(\mathrm{EtO})_{2} \mathrm{CO} \\
(\mathrm{BuO})_{2} \mathrm{CO} \\
(\mathrm{t}-\mathrm{BuO})_{2} \mathrm{CO}\end{array}$ & $\begin{array}{l}14.8784 \\
15.0941 \\
15.1608 \\
15.5216\end{array}$ & $\begin{array}{l}9.8953 \\
9.7907 \\
9.7558 \\
9.5785\end{array}$ & $\begin{array}{c}\text { 1754(Pure } \\
\text { liquid) } \\
1748\left(\mathrm{CCl}_{4}\right) \\
1746\left(\mathrm{CCl}_{4}\right) \\
1739\left(\mathrm{CCl}_{4}\right)\end{array}$ & $\begin{array}{l}1753 \\
1748 \\
1747 \\
1739\end{array}$ & $\begin{array}{c}1 \\
-0 \\
-1 \\
0\end{array}$ & $\begin{array}{c}0.06 \\
0 \\
-0.06 \\
0\end{array}$ \\
\hline $\begin{array}{c}{ }^{\mathrm{C}} \mathrm{RCO}_{2} \mathrm{H} \\
\mathrm{MeCO}_{2} \mathrm{H} \\
\mathrm{i}-\mathrm{PrCO}_{2} \mathrm{H} \\
\mathrm{BuCO}_{2} \mathrm{H} \\
\mathrm{t}-\mathrm{BuCO}_{2} \mathrm{H}\end{array}$ & $\begin{array}{c}8.8 \\
9.2275 \\
9.0824 \\
9.4431\end{array}$ & $\begin{array}{l}12.8983 \\
12.6860 \\
12.7616 \\
12.5814\end{array}$ & $\begin{array}{c}\text { 1736(Pure } \\
\text { liquid) } \\
\text { 1715(Pure } \\
\text { liquid) } \\
\text { 1722(Pure } \\
\text { liquid) } \\
\text { 1704(Pure } \\
\text { liquid) }\end{array}$ & $\begin{array}{l}1736 \\
1715 \\
1722 \\
1704\end{array}$ & $\begin{array}{l}0 \\
0 \\
0 \\
0\end{array}$ & $\begin{array}{l}0 \\
0 \\
0 \\
0\end{array}$ \\
\hline $\begin{array}{c}{ }^{\mathrm{d}} \text { Cross-RONO } \\
\text { MeONO } \\
\text { EtONO } \\
\text { PrONO } \\
\text { i-PrONO } \\
\text { BuONO } \\
\text { i-BuONO } \\
\text { s-BuONO } \\
\text { t-BuONO } \\
\text { sec- } C_{5} \mathrm{H}_{11} \text { ONO } \\
\mathrm{t}-\mathrm{C}_{5} \mathrm{H}_{11} \mathrm{ONO}\end{array}$ & $\begin{array}{l}2.4539 \\
2.5724 \\
2.6053 \\
2.6941 \\
2.6118 \\
2.6349 \\
2.7237 \\
2.8125 \\
2.7303 \\
2.8421\end{array}$ & $\begin{array}{l}7.0959 \\
7.0145 \\
6.9942 \\
6.9360 \\
6.9913 \\
6.9767 \\
6.9157 \\
6.8576 \\
6.9099 \\
6.8372\end{array}$ & $\begin{array}{l}\text { 1681(Dilute } \\
\text { solution) } \\
1675 \text { (Dilute } \\
\text { solution) } \\
1672 \text { (Dilute } \\
\text { solution) } \\
1667 \text { (Dilute } \\
\text { solution) } \\
1669 \text { (Dilute } \\
\text { solution) } \\
1669 \text { (Dilute } \\
\text { solution) } \\
1665 \text { (Dilute } \\
\text { solution) } \\
1655 \text { (Dilute } \\
\text { solution) } \\
1664 \text { (Dilute } \\
\text { solution) } \\
1653 \text { (Dilute } \\
\text { solution) }\end{array}$ & $\begin{array}{l}1682 \\
1675 \\
1672 \\
1665 \\
1670 \\
1668 \\
1663 \\
1656 \\
1664 \\
1655\end{array}$ & $\begin{array}{c}-1 \\
-0 \\
0 \\
2 \\
-1 \\
1 \\
2 \\
-1 \\
0 \\
-2\end{array}$ & $\begin{array}{c}-0.06 \\
0 \\
0 \\
0.12 \\
-0.06 \\
0.06 \\
0.12 \\
-0.06 \\
0 \\
-0.12\end{array}$ \\
\hline $\begin{array}{c}{ }^{\mathrm{e}} \mathrm{R}_{2} \mathrm{NNO} \\
\mathrm{Me}_{2} \mathrm{NNO} \\
\mathrm{Et}_{2} \mathrm{NNO} \\
\mathrm{i}-\mathrm{Pr}_{2} \mathrm{NNO} \\
\mathrm{s}-\mathrm{Bu}_{2} \mathrm{NNO}\end{array}$ & $\begin{array}{l}1.1151 \\
0.9539 \\
0.7961 \\
0.7566\end{array}$ & $\begin{array}{l}9.4593 \\
9.3547 \\
9.2471 \\
9.2209\end{array}$ & $\begin{array}{l}\text { 1460(Dilute } \\
\text { solution) } \\
\text { 1454(Dilute } \\
\text { solution) } \\
\text { 1438(Dilute } \\
\text { solution) } \\
\text { 1437(Dilute } \\
\text { solution) }\end{array}$ & $\begin{array}{l}1460 \\
1454 \\
1439 \\
1436\end{array}$ & $\begin{array}{c}0 \\
0 \\
-1 \\
1\end{array}$ & $\begin{array}{c}0 \\
0 \\
-0.07 \\
0.07\end{array}$ \\
\hline $\begin{array}{c}{ }^{\mathrm{f}} \alpha \text {-halogenated } \\
\text { aldehyde } \\
\mathrm{F}_{3} \mathrm{CCHO} \\
\mathrm{Cl}_{3} \mathrm{CCHO} \\
\mathrm{Cl}_{2} \mathrm{CHCHO} \\
\mathrm{ClCH}_{2} \mathrm{CHO} \\
\mathrm{Br}_{3} \mathrm{CCHO}\end{array}$ & $\begin{array}{c}15.2196 \\
9.7804 \\
8.3098 \\
7.4275 \\
5.0745\end{array}$ & $\begin{array}{c}9.7267 \\
12.4156 \\
13.1424 \\
13.5785 \\
14.7413\end{array}$ & $\begin{array}{c}\text { 1784(Gas) } \\
\text { 1762(Pure } \\
\text { liquid) } \\
\text { 1742(Pure } \\
\text { liquid) } \\
\text { 1748(Pure } \\
\text { liquid) } \\
\text { 1739(Pure } \\
\text { liquid) }\end{array}$ & $\begin{array}{l}1784 \\
1757 \\
1751 \\
1747 \\
1737\end{array}$ & $\begin{array}{c}0 \\
5 \\
-9 \\
1 \\
2\end{array}$ & $\begin{array}{c}0 \\
0.28 \\
-0.52 \\
0.06 \\
0.12\end{array}$ \\
\hline
\end{tabular}

Note: $v_{\text {evo }}$ the experimental values ${ }^{31} ; v_{\text {cal }}$ the calculated values according to Equation (6)-(11); $\Delta E$ the relative errors between $v_{\text {exp }}$ and $v_{\text {calc }}$; The left superscript a, b, c, d, e, f show the series of compounds

The calculated values and the experimental values are depictured on Fig. 2. We can see that the calculated values fit closely with the experimental ones. 

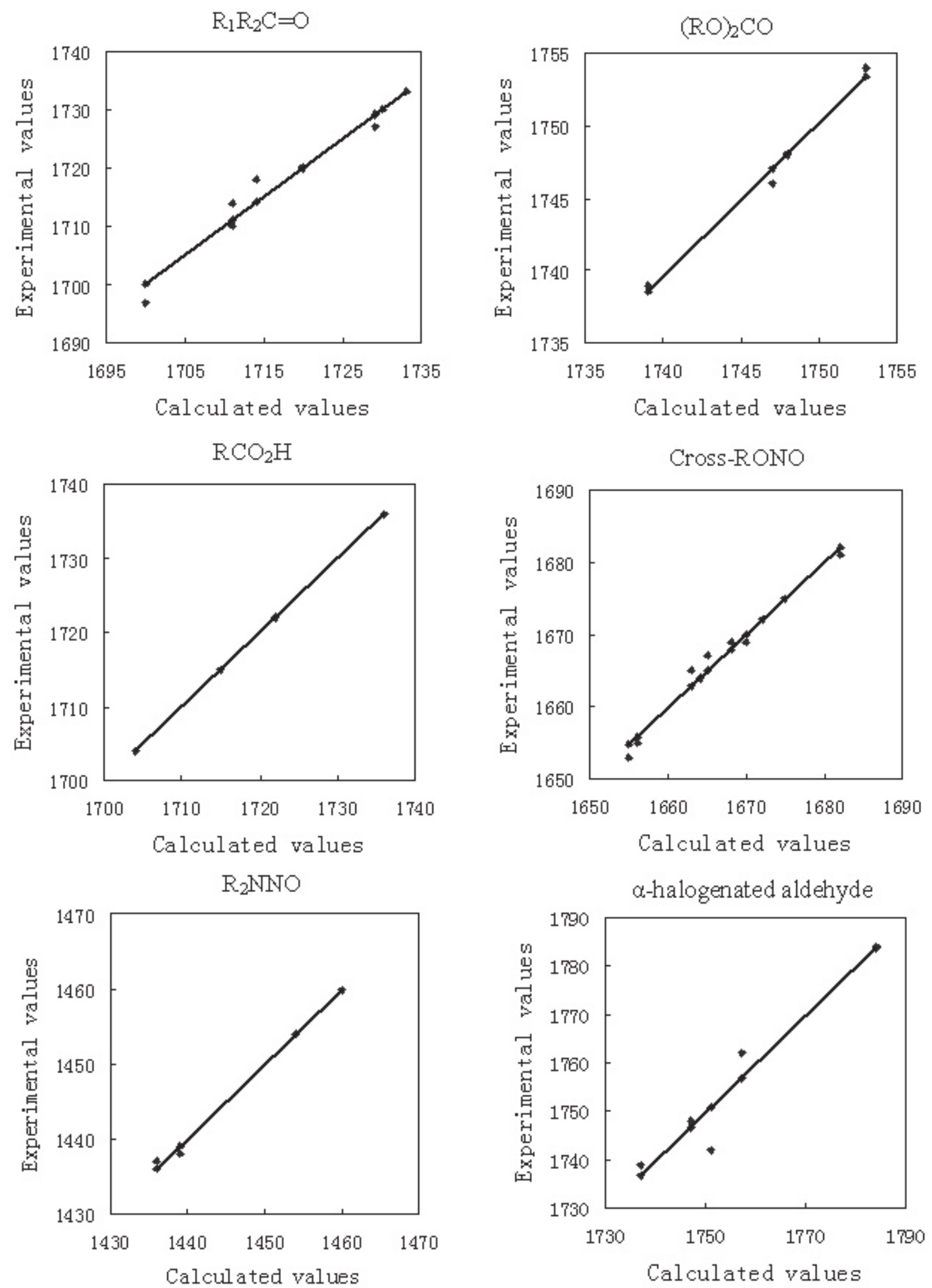

Fig. 2 Plot of experimental values versus calculated values of $v$ for 35 compounds 
To further prove the stability of the model, we used the LOO method to test the Equation (5). In this method ${ }^{28}$, we took one sample from $N$ samples, made the regression of the ionicity indices with the experimental values of the remaining $N-1$ samples, and obtained a regression equation for $N-1$ samples, then predicted the value of the sample taken-out by the regression equation. Using the same method, we got $N$ values predicted. Then $N$ values predicted were regressed with their experimental values, and the regression results such as regression constants, correlation coefficient $R_{C V}$, standard error $S_{C}$, could be used to test the stability and validity of the model. We tested the Equation (6) and Equation (9) by LOO method.

For series $\mathrm{R}_{1} \mathrm{R}_{2} \mathrm{C}=\mathrm{O}$ :

$$
\nu_{\text {exp. }}=1.015 v_{\text {calc. }}-26.6
$$

$R_{C V}=0.940, S_{C V}=4.334, n=8$.

For series Cross-RONO:

$$
\nu_{\text {exp. }}=0.978 v_{\text {car. }}-36.5
$$

$R_{C V}=0.981, S_{C V}=1.734, n=10$.

The results showed that the method using Equation (5) to study the stretching vibration frequencies of the $\mathrm{X}=\mathrm{O}$ was rational and credible.

1.2 Relationships between ionicity indices and the values of stretching vibration frequencies change

The stretching vibration frequency of the $\mathrm{C}=\mathrm{O}$ for $\alpha$-halogenated aldehyde becomes larger, because the $\alpha-\mathrm{H}$ atom is substituted by the halogen atom with larger electronegativity. The influence order of the halogens is $\mathrm{F}>\mathrm{Cl}>\mathrm{Br}>\mathrm{I}$. In addition, the change of the stretching vibration frequencies of the $\mathrm{C}=\mathrm{O}(\Delta v)$ has relation to the number of the substituted $\alpha-\mathrm{H}$ atoms. In this paper, we studied the law of change of $\Delta v$ for $\alpha$-halogenated aldehyde. According to Equation (5), we obtain

$$
\begin{aligned}
& v_{1}=\mathrm{a} / M_{(0,1,1}+\mathrm{b} / M_{(\mathrm{x}, 1}+\mathrm{c} \\
& v_{2}=\mathrm{a} N M_{(0,2)}+\mathrm{b} I N_{(\mathrm{x}, 2}+\mathrm{c}
\end{aligned}
$$

Equation (14)-Equation (15) we get

$$
\begin{aligned}
\Delta v & =\left(v_{2}-v_{1}\right) \\
& =\mathrm{a}\left(I N I_{(0), 2}-I M_{(0,1)}\right)+\mathrm{b}\left(I N I_{(\mathrm{X}, 2}-I N_{(\mathrm{X}, \mathrm{l}}\right) \\
& =\mathrm{a} \Delta I N I_{(0)}+\mathrm{b} \Delta I N I_{(\mathrm{X})}
\end{aligned}
$$

Based on Equation (16), We studied the relationship between the values of $\Delta v^{31}$ for $5 \alpha$-halogenated aldehydes and the ionicity indices of the atom $\mathrm{O}$ and $\mathrm{C}$ by using regression analysis, and gained

$$
\Delta v=1.5-665.8 \Delta I N I_{(\mathrm{C})}-1356.4 \Delta I N I_{(0)}
$$

$R=0.959, S=7.390, n=5$.

The experimental values and the calculated ones are listed on Table 2.
The result illustrated that Equation (17) better opened out the change of the stretching vibration frequencies of the $\mathrm{C}=\mathrm{O}$ for series $\alpha$-halogenated aldehydes. In fact, the ionicity index denotes the electronegativity variation between the neutral atom and the bonded atom in a molecule. The more largely electronegativity varies, the higher ionicity level of the atoms is. Forming a molecule, the electronegativity variations of the atoms in diverse chemical conditions are different too. Therefore the ionicity indices of the atoms are different from each other. All above lead to the different stretching vibration frequencies of the $\mathrm{X}=\mathrm{O}(v)$.

\section{QSSR study for ultraviolet spectrum}

The ultraviolet absorption spectrum is one of the four important spectrums in structural analysis for organic compound. Researchers are eagerly looking forward to describing the change rule of the ultraviolet absorption spectrum quantificationally. ${ }^{32}$ Because of various chromophore groups and auxochromous groups, it is difficult to construct a model which adapt to relate the ultraviolet absorption spectrum for all kinds of organic compounds. In this work, we study the quantitative structure-ultraviolet absorption spectrum relationship of 14 ketones in the same solvent simply.

As we known, the ketone is non-conjugated compound. For the carbonyl $(C=O)$ of ketones $\left(R_{1} R_{2}=O\right)$, the most important influence on ultraviolet absorption energy $(\Delta E)$ is the properties of the substituents (R). We use the ionicity indices of atom $\mathrm{C}$ and $\mathrm{O}$ to denote the chemical condition for some ketones with different Rs, describe the change rule of $\Delta E$ for $\mathrm{C}=\mathrm{O}$ by using Equation (1) with $\Delta E$ instead of $\mathrm{P}$, and obtain

$$
\Delta E=\mathrm{a} N N_{(0)}+\mathrm{b}_{(\mathrm{C})}+\mathrm{c}
$$

We do the regression analysis with $I N I_{(\mathrm{O})}, I N I_{(\mathrm{C})}$ and the experimental value of $\Delta E$, and get

$$
\Delta E=3.441+0.326 I N_{(0)}-0.313 I N_{(\mathrm{C})}
$$

$R=0.976, S=0.945, n=14$.

The experimental value of the ultraviolet absorption wavelength $(\lambda)$ is from reference ${ }^{33}$. According to the Equation (20), we can obtain the energy of electron transition of ultraviolet absorption $(\Delta E)$ for $\mathrm{C}=\mathrm{O}$.

$$
\Delta E=h v=h c / \lambda
$$

Both the calculated values and the experimental values are listed on Table 3. From the result, we find that most of the absolute errors from this work are less than that of ref. 32 .

From Fig.3, it is obviously that the calculated values accord well with the experimental ones.
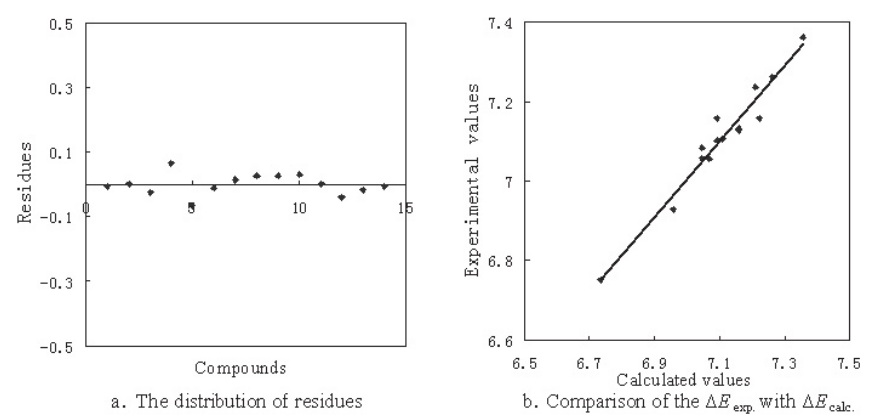

Fig. 3 Plot of experimental values versus calculated values of $\Delta E$ for 14 ketones

The Equation (19) was tested by LOO method:

$$
\Delta E_{\text {eq. }}=1.012 \Delta E_{\text {calc. }}-0.088
$$

$R_{C V}=0.968, S_{C V}=0.039, n=14$.

From the high $R_{C V}$, it can be seen that the ultraviolet absorption energy $(\Delta E)$ have a good linear correlation with the $I N I_{(\mathrm{C})}$ and $I N I_{(\mathrm{O})}$ for ketones. 
Table 2.- Comparison of the calculated values with the experimental values of $\Delta v$ for $\alpha$-halogenated aldehyde

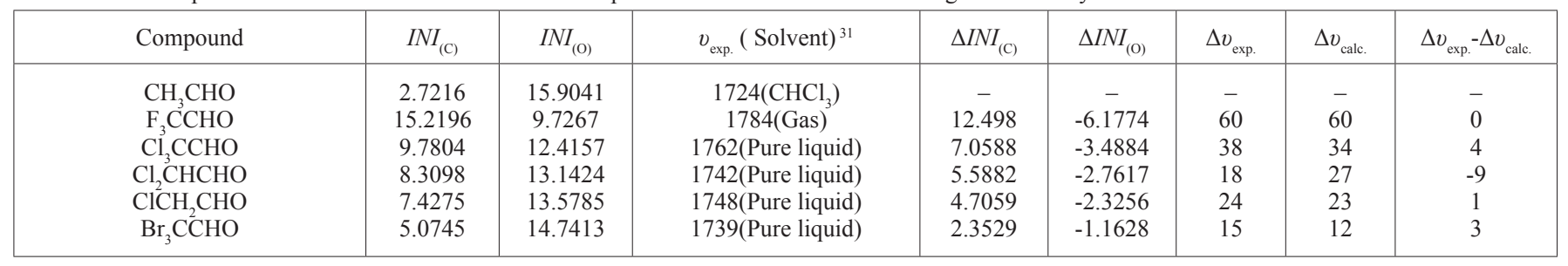

Note: $v_{\text {exp. }}$ the experimental values ${ }^{31} ; \Delta I N I_{(\mathrm{C} \text { or O) }}$ the dispersion between $I N I_{(\mathrm{C} \text { or O) }}$ for $\alpha$-halogenated aldehydes and $I N I_{(\mathrm{C} \text { or O) }}$ for $\mathrm{CH}_{3} \mathrm{CHO}$; $\Delta v_{\text {exp. }}$ the dispersion between $v_{\text {exp. }}$ for $\alpha$-halogenated aldehydes and $v_{\text {exp. }}$ for $\mathrm{CH}_{3} \mathrm{CHO} ; \Delta v_{\text {calc. }}$ the calculated values according to Equation (17)

Table 3.- The values of $\Delta E$ and $\lambda$ for 14 ketones

\begin{tabular}{|l|c|c|c|c|c|c|c|c|c|}
\hline No. & Compound & $I N I_{(\mathrm{C})}$ & $I N I_{(\mathrm{O})}$ & $\Delta E_{\text {exp. }} / 10^{-19} \mathrm{~J}$ & $\Delta E_{\text {calc. }} / 0^{-19} \mathrm{~J}$ & $\lambda_{\text {exp. }} / \mathrm{nm}$ & $\lambda_{\text {calc. }} / \mathrm{nm}$ & $\Delta \lambda^{\mathrm{a} / \mathrm{nm}}$ & $\Delta \lambda^{\mathrm{b}} / \mathrm{nm}$ \\
\hline 1 & $\mathrm{Me}_{2} \mathrm{CO}$ & 3.5804 & 15.4797 & 7.3573 & 7.3614 & 270 & 269.8 & 0.2 & 0.4 \\
\hline 2 & $\mathrm{EtMeCHO}$ & 3.7922 & 15.3721 & 7.2632 & 7.2601 & 273.5 & 273.6 & -0.1 & 0.2 \\
\hline 3 & $\mathrm{PrMeCHO}$ & 3.8471 & 15.3459 & 7.2105 & 7.2344 & 275.5 & 274.6 & 0.9 & 0.9 \\
\hline 4 & $\mathrm{Et}{ }_{2} \mathrm{CHO}$ & 4.0078 & 15.2674 & 7.2236 & 7.1585 & 275 & 277.5 & -2.5 & -2.2 \\
\hline 5 & $\mathrm{i}-\mathrm{PrMeCO}$ & 4.0078 & 15.2674 & 7.0946 & 7.1585 & 280 & 277.5 & 2.5 & 2.8 \\
\hline 6 & $\mathrm{t}-\mathrm{BuMeCO}$ & 4.2235 & 15.1628 & 7.0443 & 7.0569 & 282 & 281.5 & 0.5 & 0.9 \\
\hline 7 & $\mathrm{i}-\mathrm{PrEtCO}$ & 4.2235 & 15.1599 & 7.0693 & 7.0560 & 281 & 281.5 & -0.5 & -0.1 \\
\hline 8 & $\mathrm{PrEtCHO}$ & 4.0627 & 15.2413 & 7.1585 & 7.1328 & 277.5 & 278.5 & -1.0 & -1.0 \\
\hline 9 & $\mathrm{t}-\mathrm{BuPrCO}$ & 4.4902 & 15.0291 & 6.9579 & 6.9299 & 285.5 & 286.6 & -1.1 & -1.1 \\
\hline 10 & $\mathrm{BuEtCHO}$ & 4.0745 & 15.2355 & 7.1585 & 7.1272 & 277.5 & 278.7 & -1.2 & -1.7 \\
\hline 11 & $\mathrm{Pr}{ }_{2} \mathrm{CHO}$ & 4.1176 & 15.2151 & 7.1073 & 7.1071 & 279.5 & 279.5 & 0 & -0.4 \\
\hline 12 & $\mathrm{i}-\mathrm{BuPrCO}$ & 4.1686 & 15.1890 & 7.0443 & 7.0826 & 282 & 280.5 & 1.5 & 0.8 \\
\hline 13 & $\mathrm{t}-\mathrm{Bu}{ }_{2} \mathrm{CO}$ & 4.8667 & 14.8430 & 6.7338 & 6.7515 & 295 & 294.2 & 0.8 & 1.3 \\
\hline 14 & $\mathrm{BuPrCO}$ & 4.1294 & 15.2064 & 7.0946 & 7.1006 & 280 & 279.8 & 0.2 & -0.5 \\
\hline
\end{tabular}

Note: $\lambda_{\text {exp. }}$ the experimental values from ref. 33 and use ethyl alcohol as a solvent; $\Delta E_{\text {exp. }}$ derived from $\lambda_{\text {exp. }}$ according to Equation (20); $\Delta E_{\text {calc. }}$ the calculated values according to Equation (19); $\lambda_{\text {calc. }}$ derived from $\Delta E_{\text {calc. }}$ according to Equation (20); $\Delta \lambda \stackrel{\text { exp. }}{=} \lambda_{\text {exp. }}-\lambda_{\text {calc.; }}$; a the results of this work; $\mathrm{b}$ from ref. 32

\section{CONCLUSIONS}

The method using the ionicity index to study QSSR is successful. (1) The method is simple and accurate, and the ionicity index is convenient to be gotten. (2) The ionicity indices character the $\mathrm{X}=\mathrm{O}$ with different chemical condition around in molecules, and realize the uniqueness token of the molecule. (3) Correlation coefficients of the models range from 0.960 to 1.000 . It indicates that the ionicity index is very useful in quantitative structure-spectrum relationship study. (4) The good stability and strong predictive capability of these models are proved by LOO method.

\section{REFERENCE}

1. Wiener H, Am. Chem. Soc. 69, 17, (1947)

2. CORNWELl, Edward and CORDANO, Gianni, J. Chil. Chem. Soc. 48, 23, (2003)

3. REZA ASHRAFI, ALI, LOGHMAN, AMIR, J. Chil. Chem. Soc. 51, 968, (2006)

4. Chunhui Lu, Weimin Guo, Xiaofang Hu, Chem. Phys. Lett. 417, 11, (2006)

5. Chunhui Lu, Weimin Guo, Chunsheng Yin, Anal. Chim. Acta. 561, 96, (2006)

6. Qingsong Wang, Juan Liu, Meirong Xu, Changjun Feng, J. Wuhan Univ. Tech. 28, 117, (2006)

7. Peng Zhou, Hu Mei, Feifei Tian, Zhiliang Li, Chinese J. Anal. Chem. 34, 1096, (2006)

8. Pompe M., Randic Milan, J. Chem. Inf. Model. 46, 2, (2006)

9. Yan Chen, Changjun Feng, Chemistry, 69, 277, (2006)
10. Xihua Du, Yan Chen, Ziqiang Tang, Mingjin Li, Keying Cai, J. Nanjing Univ. Tech. 28, 98, (2006)

11. Viney Lather, Anil K Madan, J. Mol. Graph.Model. 23, 339, (2005)

12. Yovani Marrero-Poncea, Alma Huesca-Guille'nb, Froyla'n IbarraVelarde, J. Mol. Struct. 717, 67, (2005)

13. Randic M., Zupan J., Vikic-Topic D., Plavsic D., Chem. Phys. Lett. 431, $375,(2006)$

14. Estrada E., Comput. Biol. Chem. 27, 305, (2003)

15. Bajaj Sanjay, Sambi S. S., Gupta S., Madan A. K., QSAR Comb. Sci. 25, $813,(2006)$

16. Roy Kunal, Ghosh Gopinath, QSAR Comb. Sci. 25, 846, (2006)

17. Dureja H., Madan A. K. Int. J. Pharm. 323, 27, (2006)

18. Cengzhong Cao, Chinese J. Org. Chem. 18, 546, (1998)

19. Khadikar P., Mandloi M., Shrivastava A., Phadnis A., Oxid. Commun. 26, $161,(2003)$

20. You Jinglin, Jiang Guochang, Chen Hui, Xu Kuangdi, Rare Metals, 25, $431,(2006)$

21. Zhou L. P., Sun L. L., Yu Y., Lu W., Li Z. L., J. Mol. Graph. Model. 25, $333,(2006)$

22. Changming Nie, Zhonghai Li, Songnian Wen, Chinese J. Org. Chem. 21, $46,(2002)$

23. Changming Nie, Guowen Peng, Fangzhu Xiao, Shan Li, Xiaomei He, Zhonghai Li, Congyi Zhou, Chinese J. Anal. Chem. 34, 1560, (2006)

24. Changming Nie, J. Wuhan Univ. 46, 176, (2000)

25. Congyi Zhou, Changming Nie, Shan Li, Songnian Wen, Guowen Peng, Zhonghai Li, Chinese J. Inorg. Chem. 23, 25, (2007)

26. Changming Nie, Yimin Dai, Songnian Wen, Zonghai Li, Chinese J. Chromatogr. 23, 1, (2005) 
27. Changming Nie, Yimin Dai, Songnian Wen, Acta Chim. Sinica, 63, 1449, (2005)

28. Congyi Zhou, Changming Nie, Shan Li, Zhonghai Li, J. Comput. Chem. 28, 2413, (2007)

29. Congyi Zhou, Xi Chu, Changming Nie, J. Phys. Chem. B, 111, 34, 10174, (2007)

30. Congyi Zhou, Changming Nie, Bul. Chem. Soc. Japan, 80, 1504, (2007)

31. Jingxi Xie, The application of infrared spectroscopy to organic chemistry and medicinal chemistry, Science Press, Beijing, 1987.

32. Chenzhong Cao, J. Xiangtan Normal College, 19, 1, (1998) (in chinese)

33. Weast R C, Handbook of Chemistry and physics, 65thed, CRC press, INC, 1984-1985.

\section{ACKNOWLEDGMENT}

We acknowledge the support from the Science and Technology Projects of Hunan Province (No.06FJ4104) and Technology Innovation Plans of Economy Commission of Hunan Province (No.[2005]283). 